\title{
GENETIC CONTROL OF RECOMBINATION IN NEURO- SPORA CRASSA: CORRELATED REGULATION IN UNLINKED CHROMOSOME INTERVALS
}

\author{
LARS LANDNER \\ Institute of Genetics, University of Stockholm, S-11386 Stockholm, Sweden
}

Received 30.xii.70

\section{INTRODUCTION}

THE genic control of meiotic recombination is suggested by Simchen and Stamberg $(1969 a)$ to be of two general types: fine and coarse. Two important features of the fine control mechanism, according to the model proposed, are:

1. the magnitude of effect on recombination is small; and

2. only small, specific regions of the genome are affected by an allelic difference in the controlling locus.

The rec genes in Neurospora crassa have been referred to as examples of factors exerting the fine control (op. cit.). These loci have also been found to be highly region-specific in their controlling effect (Smith, 1966; Catcheside, 1969; Jha, 1969). Attempts to isolate further genes affecting intergenic recombination have been done concurrently in Drosophila melanogaster (Valentin, 1969) and Neurospora crassa (Landner, 1969) by means of selection for high and low recombination frequency in a specific chromosome interval.

In the selection work with $\mathcal{N}$ eurospora, members of a base population, formed to ensure a great genetic variability, were first tested for recombination frequency in crosses to a test strain marked with the spore colour marker asco in linkage group (L.G.) VI. Thereafter, the five isolates of each mating type that showed the highest recombination frequencies were picked out and crossed to each other in all possible combinations, thus starting the high selection line. Another selection line for low recombination was established in a similar way. Later generations were treated according to a similar scheme. A more detailed account of the selection work will be published later (Landner, in preparation).

After selection in both directions for three generations, a number of isolates were available showing strong variation in recombination frequency in the asco-centromere interval. This selected material has been used to investigate the occurrence of correlated regulation of meiotic recombination in four different chromosome intervals. The results obtained are also compared with some of the predictions made by Simchen and Stamberg (1969a).

\section{Materials AND methods}

The selection for high and for low recombination frequency was started from a base population established by a four-way cross involving the wild types Costa Rica A, Emerson Em 5256 A, Lindegren 25 a and 74-OR8-1a. After 
selection for three generations, 18 wild type isolates of each mating type were sampled, half of the isolates from the high selection line and the other half from the low one.

Four spore colour markers were used in separate test strains, namely:

bs (brown spore) in L.G. I,

ts (tanned spore) in L.G. V,

ws-1 (white spore) in L.G. VI and

ws-2 (white spore) in L.G. VI.

Allele numbers and strain numbers were as follows: asco (37402)a, FGSC 405, was crossed into several different wild-type backgrounds to obtain asco $B$, a (Cotsa Rica background), asco $C$, a (Emerson background), asco $E$, A (Lindegren background) and asco $G$, A (Emerson background). bs (AR 62) A and a, FGSC 1780 and 1781. ts (no allele number) A, FGSC 821. ws-1 (18-973) A and a, FGSC 1434 and 1435. wes-2 (NM 122) a, FGSC 1617.

The above listed markers have previously been used and described by, for example, Towe and Stadler (1964), asco; Nakamura (1966), ts; Phillips and Srb (1967), ws-1; and Perkins et al. (1969), ws-2. Information on bs was kindly given by Perkins (personal communication).

All crosses were made on Westergaard's and Mitchell's (1947) liquid crossing medium in test-tubes with filter-paper strips as support for the perithecia. Incubation temperature was $25^{\circ} \mathrm{C}$., just as in the selection work. Eleven to twelve days after fertilization of the protoperithecia (always formed by the wildtype parent), 200 asci were scored from each cross.

The joint variation in recombination frequencies in the four intervals was investigated by means of computation of correlation coefficients for every pairwise combination. The individual frequencies of second division segregation (SDS) were transformed into angles $\varnothing$ by $p=\sin ^{2} \varnothing(p=$ frequ. SDS) before statistical treatment. As, in spite of angular transformation, it could not be taken for granted that the SDS values were normally distributed, the non parametric method of computation of $\tau$, the Kendall rank correlation coefficient, was used in addition to the standard statistical method. The two methods gave substantially the same result. Only in one case (ws-2-bs) the non-parametric method gave a significant correlation, when the other method did not.

\section{Results AND Discussion}

The results from the crosses are shown in table 1 as frequencies of SDS for the different markers.

The corresponding correlation coefficients can be found in table 2. As can be seen in table 1 , the ws-1-centromere interval is a very long region. It is therefore probable that the obtained values on SDS for wes- 1 give inaccurate estimates of the recombination frequency in the region. The results from this interval are consequently disregarded from any further considerations in this analysis.

In table 2, showing the results of the correlation analysis performed on the whole material, it is demonstrated that: 
1. Highly significant correlations were obtained between recombination frequencies in the asco-centromere interval on one hand and both the bscentromere interval and the $t s$-centromere interval on the other.

2. No significant relationship was found between recombination frequencies in the asco-centromere $v s$. the ws-2-centromere intervals.

TABLE 1

Frequencies of second-division segregation (SDS) for different markers in crosses with 36 different wildtype isolates from the third generation of selection

\begin{tabular}{|c|c|c|c|c|c|c|}
\hline & $\begin{array}{c}\text { Isolate } \\
\text { No. }\end{array}$ & $\operatorname{asco} B, \mathrm{a}$ & $\operatorname{asco} C, \mathrm{a}$ & $b s, \mathrm{a}$ & $w s-1, \mathrm{a}$ & $w s-2$, a \\
\hline & $\int 365$ & 59.5 & $72 \cdot 5$ & $62 \cdot 0$ & $83 \cdot 0$ & 23.5 \\
\hline & 463 & 57.0 & $62 \cdot 0$ & $60 \cdot 0$ & $86 \cdot 0$ & $18 \cdot 5$ \\
\hline & 282 & $54 \cdot 0$ & $64 \cdot 0$ & $60 \cdot 0$ & 87.5 & 12.5 \\
\hline High & 344 & $52 \cdot 0$ & $49 \cdot 0$ & $58 \cdot 0$ & 77.0 & - \\
\hline line & 501 & $51 \cdot 0$ & $46 \cdot 0$ & $36 \cdot 5$ & 86.5 & $14 \cdot 0$ \\
\hline $\mathrm{mt} \mathrm{A}$ & 221 & $47 \cdot 0$ & $45 \cdot 0$ & 37.5 & $90 \cdot 0$ & $15 \cdot 0$ \\
\hline & 262 & 34.5 & 47.5 & 43.5 & 85.0 & $15 \cdot 5$ \\
\hline & 627 & 33.5 & $32 \cdot 0$ & $26 \cdot 5$ & 76.5 & $18 \cdot 0$ \\
\hline & 100 & 32.0 & 48.5 & $65 \cdot 0$ & 87.0 & $17 \cdot 5$ \\
\hline & CQU3 & 28.5 & $41 \cdot 0$ & $24 \cdot 0$ & $71 \cdot 0$ & $9 \cdot 0$ \\
\hline & OV1 & $26 \cdot 5$ & $19 \cdot 0$ & $42 \cdot 0$ & $89 \cdot 5$ & $19 \cdot 0$ \\
\hline & PY8 & $23 \cdot 0$ & 21.5 & $68 \cdot 0$ & 89.5 & 21.5 \\
\hline Low & NY11 & $15 \cdot 0$ & $12 \cdot 0$ & $23 \cdot 0$ & 85.5 & $15 \cdot 0$ \\
\hline line & PT5 & 14.5 & 15.5 & $24 \cdot 0$ & $70 \cdot 0$ & $16 \cdot 0$ \\
\hline $\mathrm{mt} \mathrm{A}$ & NV5 & 10.5 & 15.0 & $17 \cdot 0$ & $86 \cdot 5$ & 13.5 \\
\hline & SV4 & $10 \cdot 0$ & 25.5 & $49 \cdot 0$ & $66 \cdot 5$ & $19 \cdot 0$ \\
\hline & OT6 & $9 \cdot 5$ & $20 \cdot 0$ & 27.5 & 81.5 & $18 \cdot 5$ \\
\hline & NX9 & 8.5 & $15 \cdot 0$ & $37 \cdot 0$ & 95.5 & $12 \cdot 0$ \\
\hline & & $\operatorname{asco} E, \mathrm{~A}$ & $\operatorname{asco} G, \mathrm{~A}$ & $b s, \mathrm{~A}$ & $w s-1, \mathrm{~A}$ & $t s, \mathrm{~A}$ \\
\hline & 380 & 65.5 & $52 \cdot 0$ & $49 \cdot 0$ & $81 \cdot 5$ & $47 \cdot 0$ \\
\hline & 343 & $54 \cdot 0$ & 64.5 & $63 \cdot 0$ & 84.5 & $67 \cdot 0$ \\
\hline & 129 & 53.5 & $64 \cdot 0$ & $41 \cdot 0$ & 79.5 & 59.5 \\
\hline High & 385 & $52 \cdot 5$ & $42 \cdot 0$ & $43 \cdot 5$ & 88.5 & $45 \cdot 0$ \\
\hline line & 203 & $48 \cdot 0$ & $63 \cdot 0$ & 46.5 & 78.0 & $66 \cdot 0$ \\
\hline $\mathrm{mt} \mathrm{a}$ & 102 & $44 \cdot 0$ & 55.5 & $66 \cdot 0$ & 86.5 & 64.5 \\
\hline & 161 & $36 \cdot 0$ & 33.5 & 41.5 & 88.0 & $64 \cdot 5$ \\
\hline & 560 & $35 \cdot 5$ & 45.5 & $36 \cdot 5$ & 69.0 & $35 \cdot 5$ \\
\hline & 689 & $34 \cdot 0$ & $42 \cdot 0$ & $44 \cdot 0$ & 77.0 & 47.5 \\
\hline & Cov6 & $40 \cdot 0$ & $8 \cdot 0$ & $22 \cdot 5$ & $49 \cdot 0$ & $59 \cdot 0$ \\
\hline & QU13 & 33.5 & $42 \cdot 0$ & $41 \cdot 0$ & $76 \cdot 0$ & $51 \cdot 0$ \\
\hline & QV5 & $33 \cdot 5$ & $38 \cdot 0$ & 33.5 & 59.5 & $40 \cdot 5$ \\
\hline & SV10 & $15 \cdot 5$ & $6 \cdot 0$ & - & 79.5 & $16 \cdot 5$ \\
\hline line & NU4 & 13.5 & 38.5 & $4 \cdot 0$ & $81 \cdot 0$ & 31.5 \\
\hline $\mathrm{mt} \mathrm{a}$ & QY7 & $13 \cdot 0$ & $30 \cdot 0$ & - & $87 \cdot 0$ & $47 \cdot 5$ \\
\hline & PY2 & 13.0 & $26 \cdot 5$ & 28.5 & 88.0 & 52.5 \\
\hline & $\mathrm{QX} 1$ & $12 \cdot 5$ & 31.5 & 51.0 & 71.0 & 14.5 \\
\hline & OY3 & $12 \cdot 0$ & 36.5 & 45.5 & 65.5 & 37.5 \\
\hline
\end{tabular}

3. Strong correlations were apparent between the SDS frequencies of asco strains with different genetic backgrounds.

From these findings it was concluded that:

1. Recombination is regulated in a connected manner in the three unlinked regions studied, belonging to L.G.s I, V and VI. 
2. Different regions stituated in the same L.G. (VI), on the other hand, do not necessarily show a correlated regulation of recombination.

3. The regulation is, to a substantial degree, exerted by dominant factors.

The finding by Simchen and Stamberg (1969b) in Schizophyllum commune that "recombinational events in unlinked chromosomal segments

TABLE 2

Correlation analysis of the data given in table 1 (transformed into angles). The correlation coefficients $\mathrm{r}$ with their probabilities and the Kendall rank correlation coefficients $\tau$ are given. The $P$-values for $\tau$ are obtained by $Z$-analysis

Wild-types: mating type A:

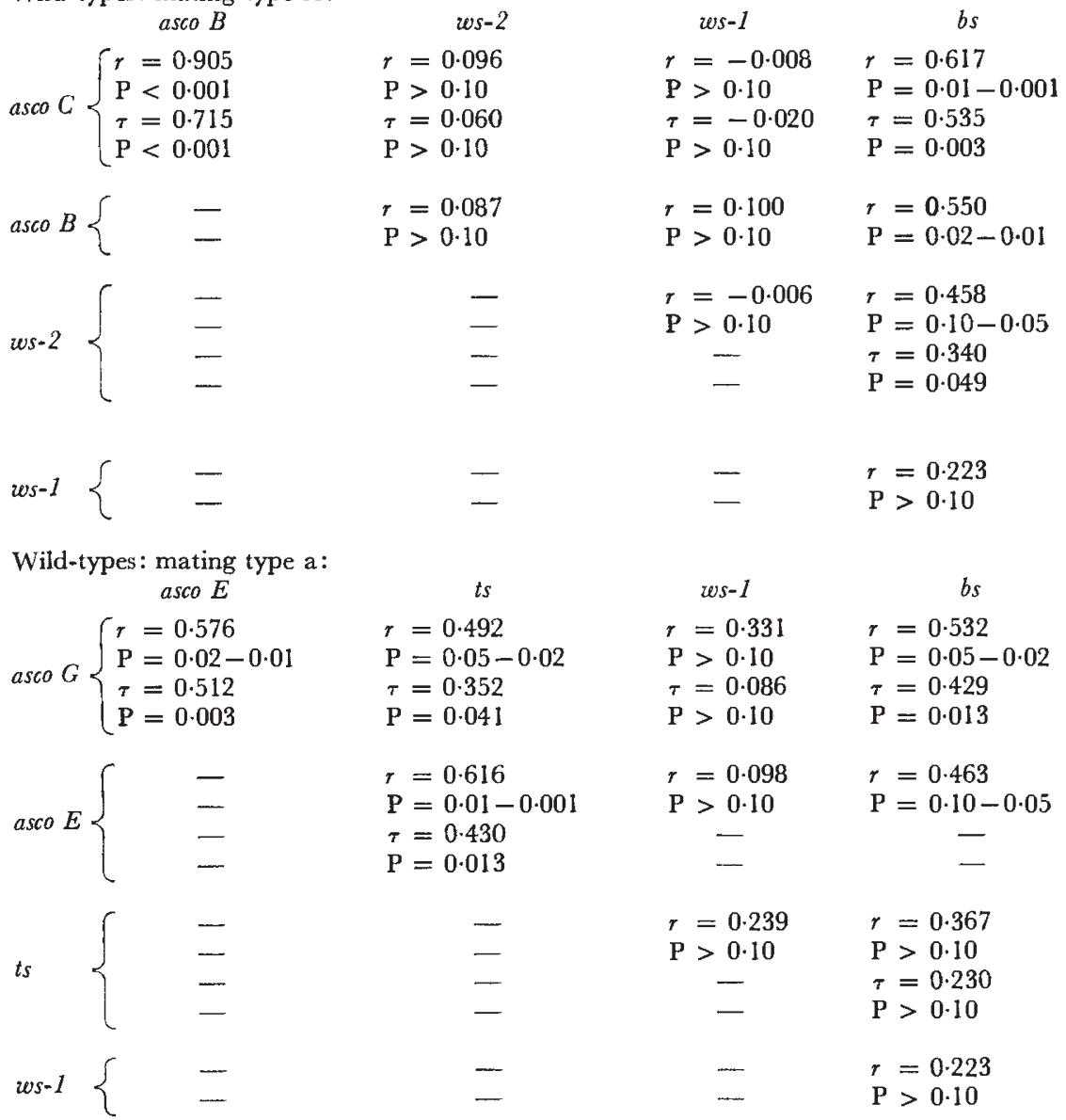

are controlled by different components of the fine control ", thus, does not seem to be quite universal: from the present work it is strongly indicated that some kind of control of recombination with fairly general effects over large parts of the genome prevails in Neurospora. This control, on the other hand, does not either seem to fulfil the requirements of the "coarse control" proposed by Simchen and Stamberg $(1969 a)$.

The tested wild-types came from two different selection lines, one selected for high recombination frequency and the other one for low. It is 
therefore quite probable that different regulating genes have accumulated in the two groups. In an attempt to further analyse the discrepancies towards Simchen's and Stamberg's model (1969a), the correlation analysis was also performed separately on the isolates from the high and those from the low line (table 3). No significant positive correlation whatever was found in the low line. The correlation coefficients obtained at comparisons within the high line, however, differed significantly from zero in two cases and in general they assumed higher values than when the same comparisons were made within the low line.

The genetic variation existing within the high selection line thus seems to be more significant for the general control of recombination than the variation within the low line. Though it cannot be precluded that this difference between the two lines is simply a result of random fixation of genes in different lines of selection, it appears more reasonable to explain

TABLE 3

Correlation analysis performed separately in the "high" and the "low" line

Wild-types: mating type A:

\begin{tabular}{|c|c|c|c|c|}
\hline & asco $B$ & $w s-2$ & $w s-1$ & $b s$ \\
\hline $\begin{array}{r}\text { High line } \\
\text { asco } C\end{array}$ & $\left\{\begin{array}{l}r=0.744 \\
P=0.05-0.02\end{array}\right.$ & $\begin{array}{l}r=0.376 \\
P>0.10\end{array}$ & $\begin{array}{l}r=0.266 \\
P>0.10\end{array}$ & $\begin{array}{l}r=0.763 \\
\mathrm{P}=0.02-0.00\end{array}$ \\
\hline $\begin{array}{r}\text { Low line } \\
\text { asco } C\end{array}$ & $\left\{\begin{array}{l}r=0.536 \\
P>0.10\end{array}\right.$ & $\begin{array}{l}r=-0.295 \\
\mathrm{P}>0.10\end{array}$ & $\begin{array}{l}r=-0.512 \\
\mathrm{P}>0.10\end{array}$ & $\begin{array}{l}r=0.153 \\
\mathrm{P}>0.10\end{array}$ \\
\hline
\end{tabular}

Wild-types: mating type a:

\begin{tabular}{|c|c|c|c|c|}
\hline & $\operatorname{asco} E$ & ts & ws-1 & $b s$ \\
\hline High line & $r=0.550$ & $r=0.464$ & $r=-0.166$ & $r=0.474$ \\
\hline asco $G$ & $\left\{\begin{array}{l}P>0.10 \\
0\end{array}\right.$ & $P>0.10$ & $P>0.10$ & $P>0.10$ \\
\hline $\begin{array}{l}\text { Low line } \\
\text { asco } G\end{array}$ & $\left\{\begin{array}{l}r=-0 \cdot 150 \\
P>0 \cdot 10\end{array}\right.$ & $\begin{array}{l}r=0.095 \\
P>0.10\end{array}$ & $\begin{array}{l}r=0 \cdot 191 \\
P>0 \cdot 10\end{array}$ & $\begin{array}{l}r=0.184 \\
\mathrm{P}>0.10\end{array}$ \\
\hline
\end{tabular}

the observation in terms of varying outcomes of selection in opposite directions. It can be assumed, then, that the recombination regulating genes accumulated in the high line have a rather low specificity with respect to region where they exert their control. The corresponding genes accumulated in the low line might be more region-specific in their action, so that when reducing recombination in the asco-centromere interval, they do not affect many (or any) other regions.

The last statement is in accordance with the observations made by Smith (1966), Catcheside (1969) and Stamberg (1969) that recombination regulating genes in all the cases tested were highly specific as to the chromosome they regulate. These authors also showed that the dominant alleles of the rec genes always reduced the frequency of recombination in the interval studied. In the present experiment, with the experimental plan used, it was noted that it is particularly the effects of dominant alleles of regulating genes that have been studied. These things taken together support the hypothesis that a very few factors, suppressing the SDSfrequency of asco, accumulated in the low line and belong to the same category of genes as the rec genes studied by the above-cited authors, i.e. distinct, "major" genes. In conclusion, it might be some elements of 
"the fine control of recombination" (cf. Stamberg, 1969) in the ascocentromere region of L.G. VI that have been isolated in the low line.

The correlation found between recombination frequencies in intervals of different L.G.s is chiefly due to factors accumulated in the high line. These factors must consequently belong to a different category of recombination regulating elements. What kind of factors are those, and how do they exert their control of recombination?

It is possible that these latter controlling factors exert their action at a quite different level of the recombination process than the region-specific factors indicated in the low line, which are thought to interfere with the breakage-reunion process in the DNA (see e.g. Jha, 1967). The level of control in the case of non-region-specific factors might be, for example, synapsis or more precisely the synthesis of the synaptonemal complex. As pointed out by, for example, Comings and Okada (1970), the entirely proteinaceous synaptonemal complex is synthesized during early meiosis. This quite extensive protein synthesis, the efficiency of which might influence the recombination frequency, must be subject to genic control. Moreover, the effects of this genic control in terms of changed recombination frequency should not be localized to limited chromosome regions, but rather affect all or most of the genome.

Another type of control of recombination that hardly can be region specific is the control mediated by the energy-producing system of the cells (Landner, 1970). Recent work by Oishi (1969), Barbour and Clark (1970) and Goldmark and Linn (1970) has demonstrated the existence of ATPdependent nucleases implicated in genetic recombination in bacteria. This carries the ATP-generating system of the cells to a more prominent position when considering the control of recombination among eucaryotes too. A control function emanating from genes determining enzymes catalysing the different steps in energy production should obviously affect the whole genome.

This general or "coarse" control of recombination should not necessarily be of the extreme (all-or-none) type, as postulated by Simchen and Stamberg (1969a). Apparently a great number of factors are involved in this control system and allelic differences in a few of them would result in only small effects on recombination. This could be visualized as a polygenic control system.

From an evolutionary point of view, the control of recombination would be exerted as follows:

The "normal" situation for the organism is to maintain complexes of polygenes affecting " fitness" held together by means of normal (dominant) alleles of recombination controlling, region-specific genes. That is, the direct control of recombination is supposed to work only in depressing direction, reducing the recombination frequency in certain regions.

Increased recombination would, according to this hypothesis, result from (1) impaired direct control function by homozygosity for the recessive allele of the controlling loci or (2) changes of more general character, concerning many different cellular functions, i.e. changes in ribosome or protein synthesis or energy metabolism (Landner, 1970). This would be the most advantageous situation for the organism: in a rapidly changing environment where the organisms meet the requirement of a rapid release of variability stored in polygenic complexes, the increase in recombination frequency must be general, and rapid (cf. Stamberg, 1969). 
The response to the environmental changes would not be efficient enough if the increase in recombination should be region-specific, and therefore an alternative system must be involved as compared to the depressing, regionspecific control prevailing under stable environmental conditions.

Thus it is quite feasible that the adaptation of recombination to a new situation is closely connected with increasing protein synthesis and/or changes in energy production.

\section{Summary}

1. Eighteen wild-type isolates of Neurospora crassa, selected for three generations for high frequency of second-division segregation (SDS) for asco and 18 selected for low frequency, have been crossed to four additional sporecolour marker strains.

2. These crosses were performed to investigate the occurrence of correlated regulation of meiotic recombination in unlinked chromosome intervals.

3. Significant positive correlations were found between the frequencies of SDS of markers in three different linkage groups.

4. The isolates from the high selection line appear to contribute to the correlation to a much greater extent than the isolates from the low line.

5 . On the basis of these results, fine and coarse controls of recombination (Simchen and Stamberg, 1969a) were discussed, and a partly new model for the control mechanisms was proposed.

Acknowledgments. - I am greatly indebted to Professor D. Perkins for valuable advice and for providing some of the strains. The providing of other strains by the Fungal Genetics Stock Center (FGSC) is also gratefully acknowledged. I also wish to thank Professor K. G. Lüning for his critical reading of the manuscript and Dr J. Valentin for many helpful discussions during the work. Sincere thanks are due to Mrs H. Andersson and A. Rudman for technical assistance.

This work was supported by a grant from the Swedish Natural Science Research Council to Drs K. G. Lüning and C. Ramel.

\section{REFERENGES}

BARBOUR, S. D., AND CLARK, A. J. 1970. Biochemical and genetic studies of recombination proficiency in Escherichia coli, I. Enzymatic activity associated with $\mathrm{rec} B^{+}$and $\mathrm{rec} \mathrm{C}^{+}$ genes. Proc. Nat. Acad. Sci. (Wash.), 65, 955-961.

CAtcheside, D. G. 1969. The role of rec genes in allelic and nonallelic recombination in Neurospora. XI Internat. Botanical Congr., Seattle, Wash. (Abstr.), p. 28.

COMINGS, D. E., AND OKADA, T. A. 1970. Mechanism of chromosome pairing during meiosis. Nature, 227, 451-456.

GOLDMARK, P. J., AND LINN, s. 1970. An endonuclease activity from Escherichia coli absent from certain rec- strains. Proc. Nat. Acad. Sci. (Wash)., 67, 434-441.

JHA, к. к. 1969. Genetic factors affecting allelic recombination at the histidine-3 locus of Neurospora crassa. Molec. Gen. Genetics, 105, 30-37.

LANDNER, L. 1969. Genetic control of recombination. I. Neurospora. Hereditas, 63, 460 (Abstr.).

LANDNER, L. 1970. Variation of recombination frequency in Neurospora crassa following temperature changes prior to and during meiosis and evidence for a premeiotic sensitive stage. Molec. Gen. Genetics, 109, 219-232.

NAKAmURA, K. 1966. Heterogeneity in crossing-over frequency in Neurospora. Genetica, 37, 235-246.

orshi, M. 1969. An ATP-dependent deoxyribonuclease from Escherichia coli with a possible role in genetic recombination. Proc. Nat. Acad. Sci. (Wash.), 64, 1292-1299. 
PERKINS, D. D., NEWMEYLR, D., TAYLOR, \&. W., AND BENNETT, D. C. 1969. New markers and map sequences in Neurospora crassa, with a description of mapping by duplication coverage, and of multiple translocation stocks for testing linkage. Genetica, 40, 247-278.

PHILliPS, R. L., AND SRB, A. M. 1967. A new white ascospore mutant of Neurospora crassa. Can. 7. Genet, Cytol., 9, 766-775.

simchen, G., AND StAmberg, J. 1969a. Fine and coarse controls of genetic recombination. Nature, 222, 329-332.

SIMCHEN, G., AND STAMBERG, ]. 1969b. Genetic control of recombination in Schizoplayllum Commune: Specific and independent regulation of adjacent and non-adjacent chromosomal regions. Heredity, 24, 369-381.

Smrth, B. R. 1966. Genetic controls of recombination. Heredity, 21, 481-498.

StAmberg, J. 1969. Genetic control of recombination in Schizophyllum Commune: The occurrence and significance of natural variation. Heredity, 24, 361-368.

TOWE, A. M., AND STADLER, D. R. 1964. Effects of temperature on crossing over in Nearospora. Genetics, 49, 577-583.

valentin, J. 1969. Genetic control of recombination. II. Drosophila. Hereditas, 63, 470 (Abstr.).

WESTERGAARD, M., AND MITCHELl, H. K, 1947. A synthetic medium favouring sexual reproduction. Amer. 7. Bot., 34, 573-577. 